\title{
Tailored microstructures and strengthening mechanisms in an additively manufactured dual- phase high-entropy alloy via selective laser melting
}

\author{
Shuncun Luo, Yue Su and Zemin Wang*
}

\begin{abstract}
Dual-phase high-entropy alloys (DP-HEAs) with excellent strength-ductility combinations have attracted scientific interests. In the present study, the microstructures of $\mathrm{AlCrCuFeNi}_{3.0}$ DP-HEA fabricated via selective laser melting (SLM) are rationally adjusted and controlled. The mechanisms engendering the hierarchical microstructures are revealed. It is found that the $\mathrm{AlCrCuFeNi}_{3.0}$ fabricated by SLM at the scanning speed of $400 \mathrm{~mm} \mathrm{~s}^{-1}$ falls into the eutectic coupled zone, and increasing the scanning speed will make this composition deviate away from the eutectic coupled zone due to the increased cooling rate. The enrichment of $\mathrm{Cr}$ and $\mathrm{Fe}$ solutes with large growth restriction values ahead of the solid/ liquid interface can develop a constitutional supercooling zone, thus facilitating the heterogeneous nucleation and nearequiaxed grain formation. The synergy of the near-eutectic DP nano-structures and near-equiaxed grains instead of columnar ones effectively suppresses cracking for the as-built DP-HEA. During the tensile deformation, the intergranular back stress hardening similar to the grain-boundary strengthening is discovered. Meanwhile, the near-eutectic microstructures comprised of soft face-centered cubic and hard ordered bodycentered cubic (B2) DP nano-structures lead to plastic strain incompatibility within grains, thus producing the intragranular back stress. The $\mathrm{Cr}$-rich nano-precipitates inside the $\mathrm{B} 2$ phase are found to be sheared by dislocation gliding and can complement the back stress. Additionally, multiple strengthening mechanisms are physically evaluated, and the back stress strengthening contributes obviously to the high performances of the as-built DP-HEA.
\end{abstract}

Keywords: high-entropy alloy, selective laser melting, hierarchical microstructures, back stress, strengthening mechanism

\section{INTRODUCTION}

High-entropy alloys (HEAs) have attracted significant scientific interests owing to their special mechanical performances and application prospects [1,2]. Among HEAs, face-centered cubic (FCC) HEAs have superior ductility and have been extensively studied [3-5]. However, many FCC single-phase HEAs generally show insufficient strength for engineering applications [6]. To overcome this drawback, precipitation hardening $[7,8]$, interstitial solute strengthening $[9,10]$, heterogeneous grain structure $[11,12]$ or multi-phase structure [13] have been applied. Especially, body-centered cubic (BCC) plus FCC dual-phase (DP) or multi-phase HEAs can achieve excellent strength-ductility combinations [14].

Selective laser melting (SLM), a flexible additive manufacturing technique, provides great potential to directly fabricate HEAs with improved comprehensive properties $[15,16]$. Currently, SLM-fabricated FCC HEAs including FeCoCrNi [17,18], $\mathrm{Al}_{0.5} \mathrm{CoCrFeNi}$ [19], CoCrFeNiMn [20-22] and C-containing CoCrFeNi [23,24], as well as BCC HEAs including AlCoCuFeNi [25], AlCrCuFeNi [26] and AlCoCrFeNi [27], have been widely studied by researchers. Recently, for the first time, FCC plus BCC $\mathrm{AlCrCuFeNi}_{x}$ DP-HEAs were produced successfully by using SLM and the crack-free $\mathrm{AlCrCuFeNi}{ }_{3}$ DP-HEA was acquired [28]. Also, the SLM-built $\mathrm{AlCrCuFeNi}_{3}$ DPHEA possesses a hierarchically heterogeneous microstructure and enhanced strength-ductility combination. However, a fast cooling rate and steep thermal gradient easily lead to cracking and performance degradation for SLM-built HEAs containing the BCC-structured phase $[25,26]$. Why the cracks can be effectively eliminated in the SLM-built FCC plus BCC AlCrCuFeNi ${ }_{3}$ DP-HEA is not clear. Moreover, the mechanisms engendering the hierarchical microstructures have never been revealed, and the strengthening mechanisms answerable for the high performances of the SLM-built $\mathrm{AlCrCuFeNi}_{3} \mathrm{DP}$ -

Wuhan National Laboratory for Optoelectronics, Huazhong University of Science and Technology, Wuhan 430074, China

*Corresponding author (email: zmwang@hust.edu.cn) 
HEA remain unknown.

In the present study, we first adjust and control the microstructure of $\mathrm{AlCrCuFeNi}{ }_{3}$ DP-HEA fabricated by using SLM under different laser energy inputs and then reveal the mechanisms engendering the hierarchical microstructures. The reason why the cracks can be effectively eliminated in the as-built DP-HEA is discovered. The deformed microstructures are also studied to reveal the strengthening mechanisms. Finally, effective and back stresses are physically evaluated.

\section{EXPERIMENTAL SECTION}

In this study, AlCrCuFeNi HEA spherical powders and high purity (> 99.9 wt.\%) Ni spherical powders were blended for $12 \mathrm{~h}$ using a low-energy ball mill to achieve the designed $\mathrm{AlCrCuFeNi}_{3}$ composition [28]. The scanning electron microscopy (SEM) morphology of the blended powders is shown in Fig. 1a, it is clear that the $\mathrm{AlCrCuFeNi}$ powders and $\mathrm{Ni}$ powders are blended uniformly with each other. Utilizing a self-developed SLM equipment (LSNF-1) [29], bulk samples $\left(7 \times 7 \times 7 \mathrm{~mm}^{3}\right)$ were built (laser power $200 \mathrm{~W}$, layer thickness $20 \mu \mathrm{m}$, hatching spacing $0.08 \mathrm{~mm}$ ) along the build direction in the pure argon atmosphere with low $\mathrm{H}_{2} \mathrm{O}$ and $\mathrm{O}_{2}$ contents $(<40 \mathrm{ppm})$. This was done at different laser scanning speeds (corresponding to different energy inputs): 400, 600, 800 and $1000 \mathrm{~mm} \mathrm{~s}^{-1}$ (labeled V400, V600, V800 and V1000 in this work). The detailed scanning strategy has been represented in previous research [26].

$\mathrm{X}$-ray diffractometer (XRD) with $\mathrm{Cu} \mathrm{Ka}$ radiation was used for phase identification. The microstructures of the as-built samples were characterized by using SEM, electron probe microanalysis (EPMA), electron backscatter diffraction (EBSD) and transmission electron microscopy (TEM). The SEM and EBSD samples were prepared by polishing and then electropolishing in $90 \mathrm{vol} \%$ methanol and 10 vol.\% perchloric acid at $0^{\circ} \mathrm{C}$. The TEM samples were prepared by grinding the slices into a thickness of $\sim 45 \mu \mathrm{m}$. Then the slices were punched into disks (diameter of $3.0 \mathrm{~mm}$ ). Finally, the TEM disks were electropolished by an automatic twin-jet electropolisher in 90 vol.\% methanol and 10 vol.\% perchloric acid at $-30^{\circ} \mathrm{C}$. The dog-bone-shaped tensile specimens (gauge length $20.0 \mathrm{~mm}$, width $5.0 \mathrm{~mm}$, thickness $1.5 \mathrm{~mm}$ ) were built, as representatively illustrated in Fig. 1b. At room temperature, uniaxial tension tests were performed on a Zwick testing machine at a strain rate of $1 \times 10^{-3} \mathrm{~s}^{-1}$. The loading direction of tensile specimens is perpendicular to the build direction of laser deposition. All tensile processes were repeated for three times. The post-deformed microstructures near the fracture parallel to the loading direction, which corresponds to the $X Y$ plane (as marked by a blue box in Fig. 1b) of the as-built tensile specimen, were studied by TEM. It should be noted that the SLMbuilt specimens generally exhibit extreme $<100>$ crystallographic texture in the build direction due to the process characteristic of SLM. Thus for rational inference and calculation of the tensile properties of the specimen, only the tensile properties perpendicular to the build direction were studied in this work. The deformed microstructures corresponding to the $X Y$ plane have random or weak texture.

\section{RESULTS AND DISCUSSION}

\section{Microstructure and crack control}

Fig. 2a shows the XRD diagrams of the as-built samples at different scanning speeds. FCC and BCC phases are identified for all the as-built $\mathrm{AlCrCuFeNi}_{3} \mathrm{HEAs}$. Also, the weak (100) diffraction peak appears at $2 \theta=31.1^{\circ}$, indicating the occurrence of an ordered BCC (B2) phase. Other diffraction peaks of the $\mathrm{B} 2$ phase including the
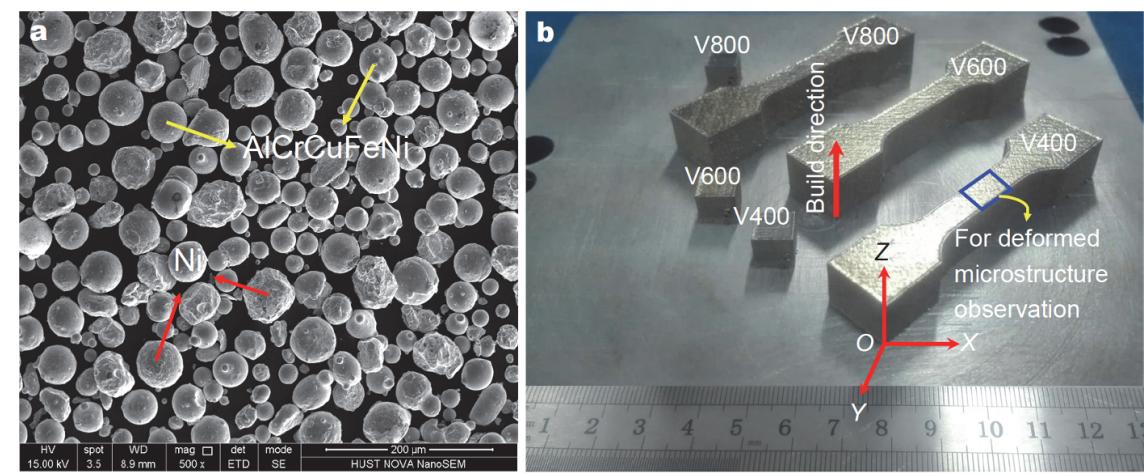

Figure 1 (a) SEM morphology of the blended $\mathrm{AlCrCuFeNi}_{3}$ powders; (b) The as-built dog-bone-shaped tensile specimens and cubic specimens of $\mathrm{AlCrCuFeNi}_{3} \mathrm{HEA}$. 

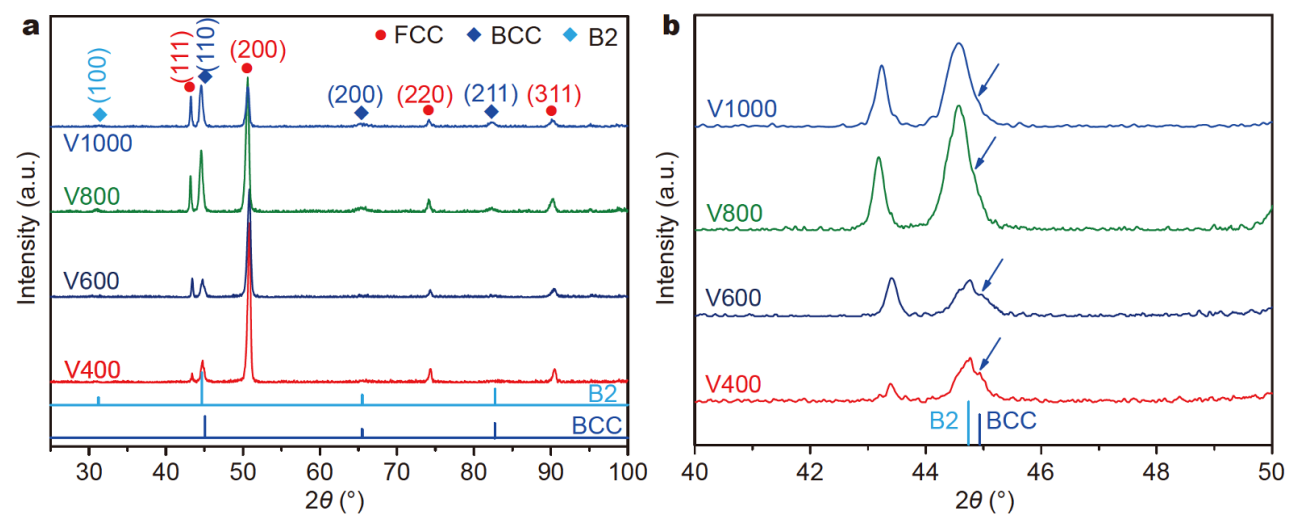

Figure 2 (a) XRD diagrams of the as-built samples at different scanning speeds; (b) partial XRD diagrams of the as-built samples at different scanning speeds. B2 denotes the ordered BCC phase.

(110), (200) and (211) overlap with those of the disordered BCC phase. Certainly, the (110) peak of the BCC and $\mathrm{B} 2$ phases can be partially distinguished, as shown in the partial XRD pattern in Fig. 2b. The left (110) peak corresponds to the $\mathrm{B} 2$ phase which is enriched in $\mathrm{Al}$ (EPMA proves that subsequently) with large atomic radius, while the right (110) peak should be corresponding to the BCC phase which is enriched in Cr (TEM proves that subsequently) with relatively small atomic radius. To better distinguish the BCC and B2 phases, the peaks of the $\mathrm{BCC}$ and $\mathrm{B} 2$ phases are separately pointed out at the bottom in Fig. 2a. The lattice parameters of the FCC, BCC and $\mathrm{B} 2$ phases for the $\mathrm{V} 400$ sample are determined to be $3.606,2.859$, and $2.864 \AA$, respectively. Moreover, as the scanning speed increases, the relative content of the BCC/ B2 phases increases. At the microscale, SEM and EBSD observations were conducted. Fig. 3 shows the backscattered electron (BSE) images and EBSD phase maps with high-angle grain boundaries (HAGBs, with misorientation larger than $15^{\circ}$ ) on the $X Z$ plane for the asbuilt samples. It can be found that the V400 sample possesses good processability because no cracks are detected in the microstructure (Fig. 3a). Meanwhile, nearequiaxed grains are observed according to the EBSD phase map with HAGBs in the V400 sample (Fig. 3b). As marked with white arrows in Fig. $3 \mathrm{c}-\mathrm{h}$, microcrack starts to appear within the BCC single-phase zone for the V600 sample and its quantity further increases with the increasing scanning speed, which suggests that the processability is deteriorated when the scanning speed increases for the SLM-fabricated $\mathrm{AlCrCuFeNi}_{3}$ HEAs. Moreover, as the scanning speed rises from 400 to $1000 \mathrm{~mm} \mathrm{~s}^{-1}$, the
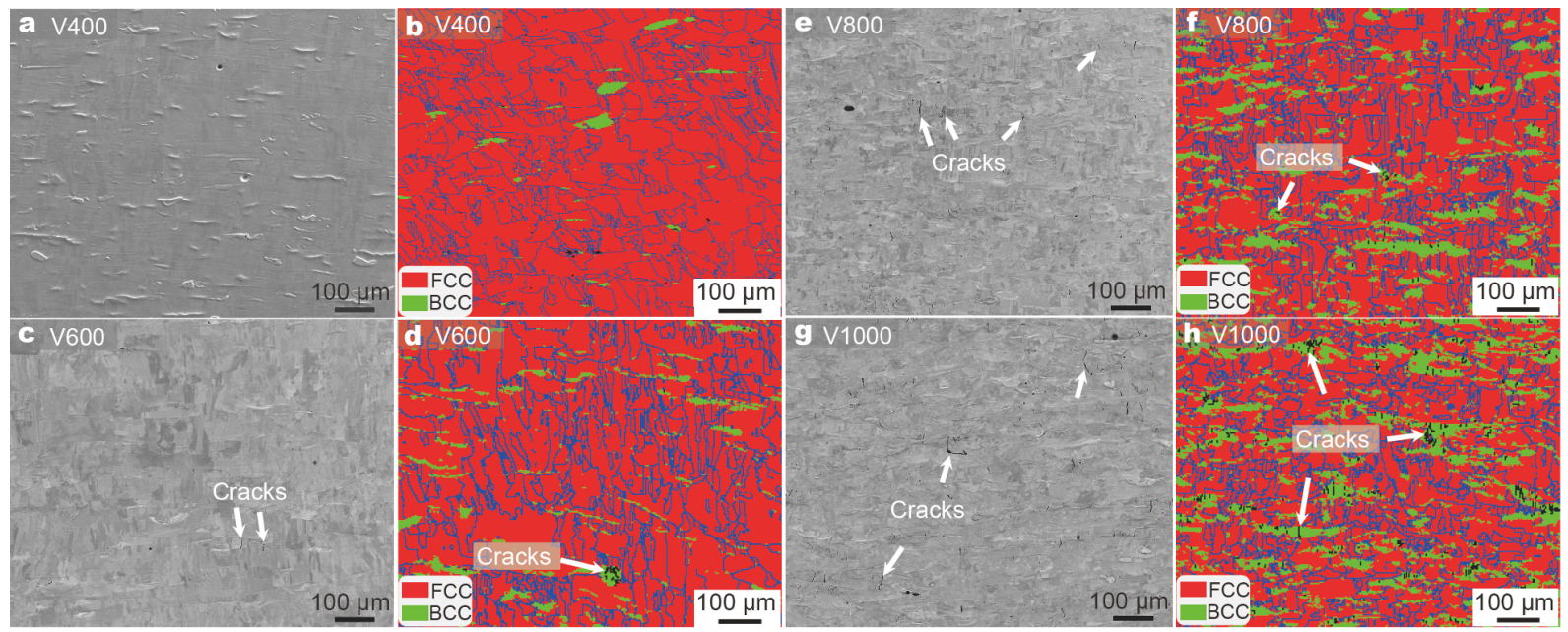

Figure 3 BSE images and EBSD phase maps with HAGBs of the as-built samples on XZ plane: (a, b) V400; (c, d) V600; (e, f) V800; (g, h) V1000. 
average grain size decreases from 21.6 to $14.7 \mu \mathrm{m}$. Meanwhile, the fraction of the FCC phase decreases while that of the BCC phase increases, basically agreeing well with the XRD results. It should be noted that the FCC grains are just detected by EBSD at the microscale. In fact, at high magnification, the FCC grains may contain lamellar nano-structures composed of FCC and BCC/B2, which will be confirmed by TEM subsequently.

To better study the microstructure inside the grains, the crack-free V400 sample was chosen for TEM observation. A bright-field TEM micrograph of the as-built V400 sample on the $X Z$ plane at the [001] zone axis (Z.A.) is displayed in Fig. 4a. Alternating lamellar nano-structure patterns are formed along the build direction within the grain, thus it can be deduced that the solid/liquid (S/L) interface exhibits cellular growth during the rapid solidification. The selected area diffraction patterns (SADPs) are shown in the insets, it can be found that the lamellar structure labeled by a yellow circle is disordered FCC phase, while the lamellar structure labeled by a purple circle is ordered BCC (B2) phase due to the occurrence of superlattice diffraction spots (labeled with dotted line rings in the SADP). Fig. $4 \mathrm{~b}$ illustrates a high-angle an- nular dark-field scanning TEM (HAADF-STEM) image of the white dashed box in Fig. 4a. It is discovered that profuse near-spherical nano-precipitates appear inside the $\mathrm{B} 2$ phase. Moreover, massive dislocations are verified within the FCC phase, indicating a high level of residual stress remained in the as-built sample after non-equilibrium rapid solidification. Fig. 4c displays a high-resolution TEM (HRTEM) micrograph of the white dashed box in Fig. 4b, which depicts the nano-precipitates inside the B2 phase near the FCC phase. The fast-Fouriertransformation (FFT) patterns in the inset confirm that the nano-precipitates are disordered BCC (A2) phases, which are embedded into the $\mathrm{B} 2$ matrix. The coherent interface between the $\mathrm{B} 2$ and $\mathrm{A} 2$ phases is also verified by the FFT patterns. An HRTEM micrograph (Fig. 4d) shows different orientations of the A2 nano-precipitates inside the B2 matrix, as indicated by the generation of diffraction rings indexed $\{011\},\{002\}$, and $\{022\}$ crystalplane indices in the FFT pattern. According to the TEM image, the mean particle size and the relative volume fraction of the A2 nano-precipitates inside the B2 phase are statistically determined to be about $8 \mathrm{~nm}$ and 58.5\%, respectively. Therefore, we can conclude that the as-built
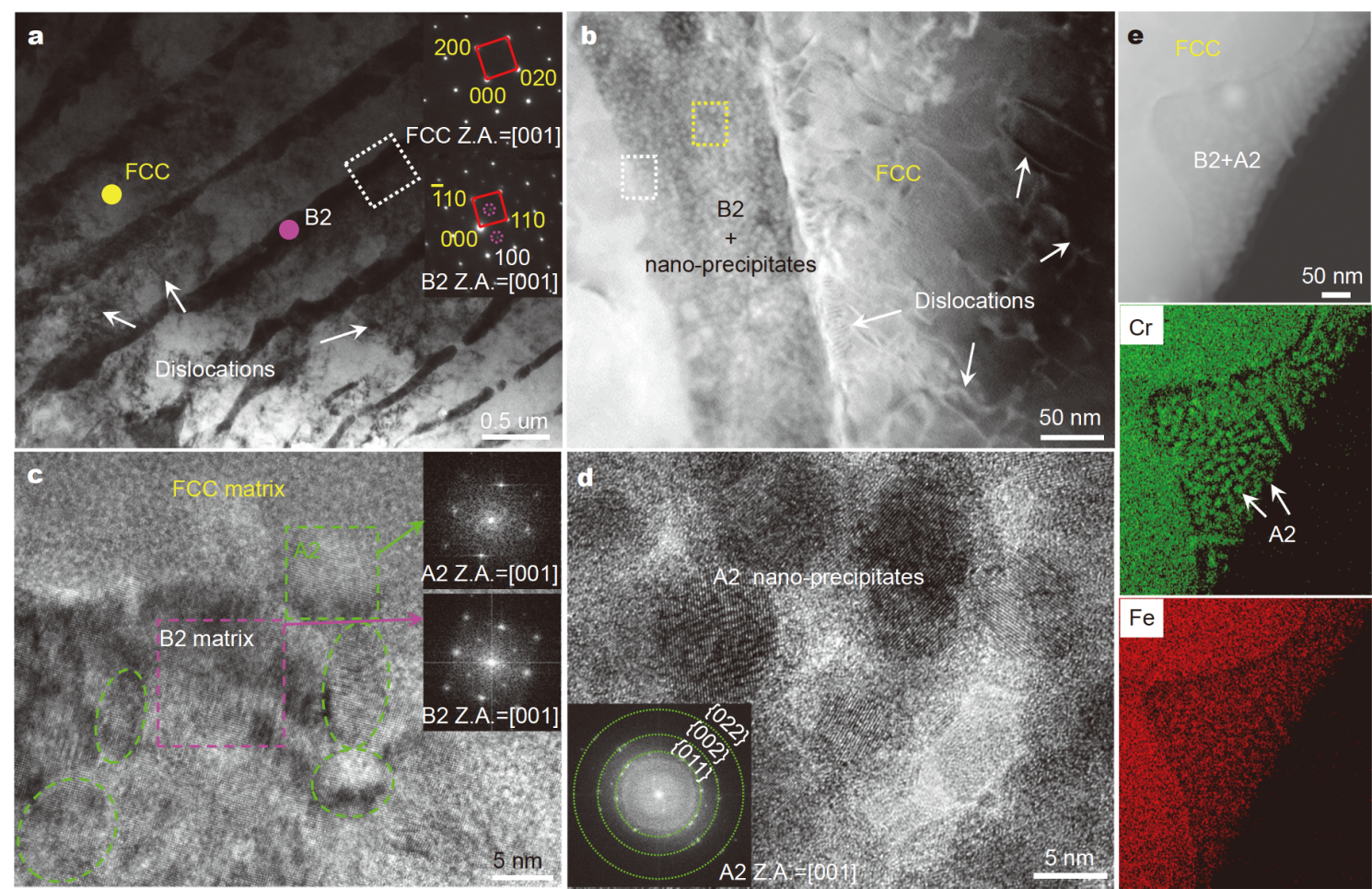

Figure 4 (a) Bright-field TEM micrograph inside the grains of the V400 sample on the XZ plane at the Z.A. of [001]; (b) HAADF-STEM micrograph of the white dotted box in (a); (c) HRTEM micrograph of the white dotted box in (b); (d) HRTEM micrograph of the yellow dotted box in (b); (e) HAADF-STEM micrograph, with the corresponding STEM-EDS images of $\mathrm{Cr}$ and $\mathrm{Fe}$ shown below. 
V400 sample shows modulated FCC + B2/A2 DP nanostructures. Fig. 4e depicts an HAADF-STEM micrograph of the DP nano-structures, and the corresponding STEMenergy dispersive X-ray spectroscopy (EDS) maps of $\mathrm{Cr}$ and $\mathrm{Fe}$ are shown below. Clearly, the FCC phase is enriched with $\mathrm{Fe}$ and $\mathrm{Cr}$, while the $\mathrm{A} 2$ nano-precipitate mainly contains $\mathrm{Cr}$ and a small amount of Fe.

The EPMA results of the V400 sample are shown in Fig. 5. It is found that FCC phase is abundant in $\mathrm{Cr}$ and $\mathrm{Fe}$, which is consistent with the result of STEM-EDS shown in Fig. 4e. B2 phase is abundant in $\mathrm{Cu}$ and $\mathrm{Al}$. Only Ni is nearly uniformly distributed.

It is hard to prepare the TEM foils by twin-jet electropolishing when cracks exist. Thus high-resolution SEM was conducted to study the phase evolution and cracking behavior. Fig. $6 \mathrm{a}$ and $\mathrm{b}$ show the high-resolution SEM images, which compare the lamellar DP nanostructures within a grain for the as-built V400 and V1000 samples on the $X Z$ plane, respectively. It can be discovered that the fraction of B2/A2 phases increases obviously as the scanning speed increases from 400 to $1000 \mathrm{~mm} \mathrm{~s}^{-1}$. Fig. $6 \mathrm{c}$ shows a high-resolution SEM image of cracks in the as-built V1000 sample on the $X Z$ plane. Isolated B2/A2 phases appear. Also, the cracks initiate and propagate within the isolated B2/A2 phases. These are consistent with the above EBSD observation. However, the cracks are redirected near the boundaries (marked by the yellow dashed line in Fig. 6c) between the isolated B2/A2 phases and the lamellar DP zone and are effectively stopped inside the lamellar DP nano-structures. The magnified SEM image of the red dashed box in Fig. $6 c$ depicting the crack termination is shown in Fig. $6 \mathrm{~d}$. It can be confirmed that the lamellar DP nanostructures comprised of soft FCC phase and hard B2/A2 phases can effectively eliminate the cracks in the as-built $\mathrm{AlCrCuFeNi}_{3} \mathrm{HEA}$.

\section{Mechanisms engendering the hierarchical microstructures}

In the V400 sample, the microstructure exhibits universal alternating lamellar DP nano-structures, suggesting that the $\mathrm{AlCrCuFeNi}_{3.0}$ alloy fabricated by SLM at the scanning speed of $400 \mathrm{~mm} \mathrm{~s}^{-1}$ is a near-eutectic HEA. It has been reported that the eutectic composition is similar to $\mathrm{AlCrCuFeNi}_{2.0}$ in the as-cast state $[30,31]$. Thus, the SLMfabricated $\mathrm{AlCrCuFeNi}_{3.0}$ at the scanning speed of $400 \mathrm{~mm} \mathrm{~s}^{-1}$ falls into the eutectic coupled zone under the non-equilibrium rapid solidification condition, thus forming the near-eutectic microstructure.

Among the five elements, the $\mathrm{Fe}, \mathrm{Cr}$ and $\mathrm{Ni}$ possess a similar chemical activity and atomic radius. Moreover, in terms of the design strategy of eutectic HEAs using mixing enthalpy [32,33], the mixing enthalpy between them is close to zero. Therefore, the $\mathrm{Fe}, \mathrm{Cr}$ and $\mathrm{Ni}$ can be completely soluble and easily form a solid solution. In contrast, the $\mathrm{Al}$ and $\mathrm{Ni}$ exhibit very negative mixing enthalpy, thus the atomic pair of $\mathrm{Al}$ and $\mathrm{Ni}$ also shows a very high combination trend. $\mathrm{Cu}$ shows very positive mixing enthalpy with $\mathrm{Fe}$ and $\mathrm{Cr}$ but negative mixing
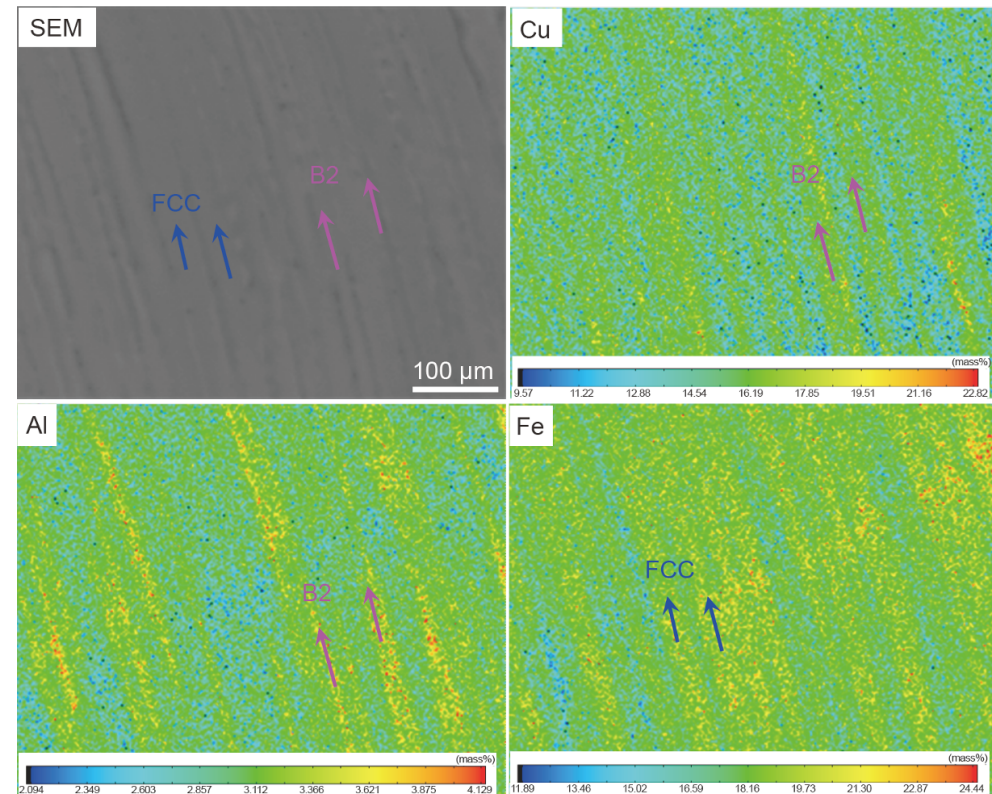

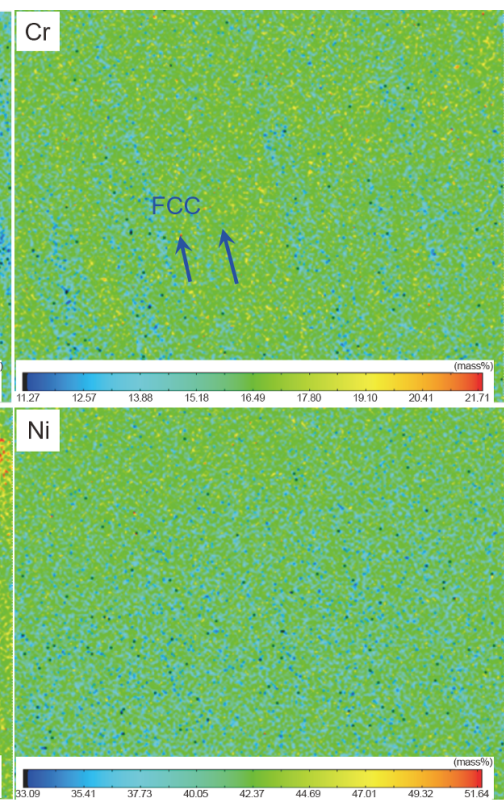

Figure 5 EPMA maps of element distribution for the V400 sample on the $X Z$ plane. 


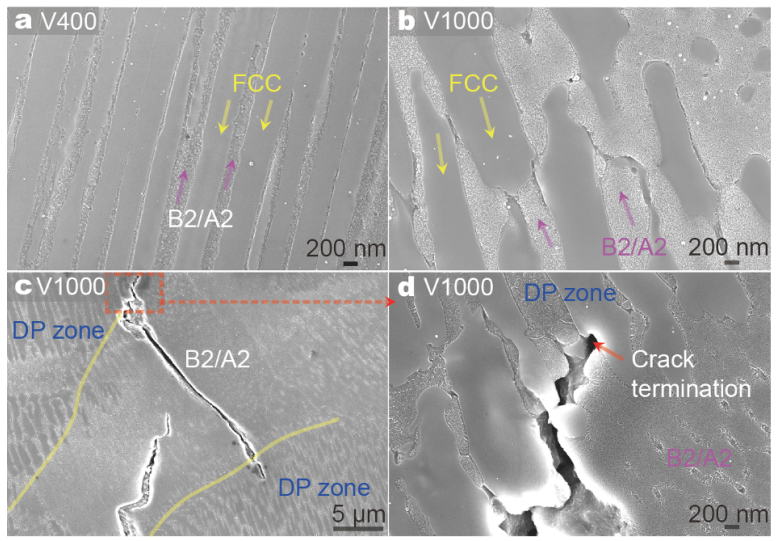

Figure 6 (a, b) High-resolution SEM images of the lamellar DP nanostructures within a grain for the as-built V400 and V1000 samples on the $X Z$ plane; (c) high-resolution SEM image of cracks in the as-built V1000 sample on the $X Z$ plane; (d) magnified SEM image of the red dotted box in $(\mathrm{c})$.

enthalpy with $\mathrm{Al}$ [34], thus $\mathrm{Cu}$ prefers to combine with $\mathrm{Al}$. As $\mathrm{Al}$ is a strong BCC stabilizer, the combination of $\mathrm{Al}, \mathrm{Ni}$ and $\mathrm{Cu}$ will tend to form the ordered $\mathrm{B} 2$ phase, while the combination of $\mathrm{Fe}, \mathrm{Cr}$ and $\mathrm{Ni}$ will form the FCC phase.

Fig. 7a-c schematically illustrate the process of eutectic reaction. The $\mathrm{Fe}, \mathrm{Cr}$ and $\mathrm{Ni}$ atoms will precipitate preferentially to form the prevenient FCC phase due to their high melting points during solidification (Fig. 7a). At the same time, the redundant $\mathrm{Al}$ and $\mathrm{Cu}$, which are very hard to combine with Fe and $\mathrm{Cr}$ in the FCC phase, are rejected at the solidification front into the liquid along the S/L interface. These prompt the nucleation of ordered B2 phase between the prevenient FCC phases (Fig. 7b). Then, the $\mathrm{Fe}$ and $\mathrm{Cr}$ atoms in the $\mathrm{B} 2$ phases separate out. This will lead to an increased $\mathrm{Fe}$ and $\mathrm{Cr}$ concentrations in the liquid with the advancing of solidification front due to the lower concentrations of $\mathrm{Fe}$ and $\mathrm{Cr}$ in the $\mathrm{B} 2$ phase than in the liquid. Consequently, the nucleation of the FCC phase is promoted again. Such continuous alternating nucleation and growth leads to the formation of FCC ( $\mathrm{Fe}-\mathrm{Cr}$ rich) and $\mathrm{B} 2(\mathrm{Cu}-\mathrm{Al}$ rich) DP structures. Due to the cellular growth characteristic ahead of the S/L interface during the rapid solidification, the FCC and B2 DP structures exhibit lamellar characteristics along the build direction on the $X Z$ plane (Fig. 7c). This can be confirmed by the above high-resolution SEM result (Fig. 6a) in the V400 sample. The high cooling rate and the sluggish diffusion effect of HEAs prevent the growth of eutectic phases, thus generating nanoscale DP structures. The FCC and B2 DP nano-structures on the $X Y$ plane for the V400 sample are schematically illustrated in Fig. 7d,
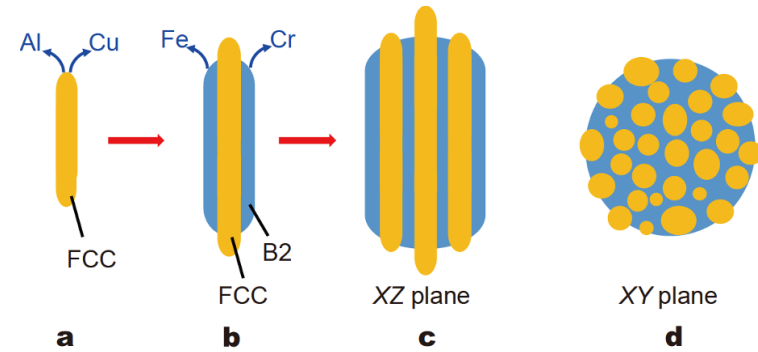

Figure 7 Schematic diagrams: $(a-c)$ alternating nucleation and growth during the eutectic reaction; (c) FCC and B2 DP nano-structures on the $X Z$ plane; (d) FCC and B2 DP nano-structures on the $X Y$ plane.

the FCC cell is nearly encircled by the $\mathrm{B} 2$ phase. As the temperature drops, the solid solubilities of atoms, especially the $\mathrm{Cr}$ atom with a higher melting point, are significantly reduced in the solid B2 phase, which mainly causes the formation of $\mathrm{Cr}$-rich $\mathrm{A} 2$ nano-precipitates via solid-state decomposition of the $\mathrm{B} 2$ phase. This can be verified by the STEM-EDS map in Fig. 4e, in which the A2 precipitates mainly contain $\mathrm{Cr}$ and a slight amount of $\mathrm{Fe}$. When the scanning speed increases, the cooling rate further increases, meanwhile, the fraction of B2/A2 phases increases (Fig. 6a, b). This indicates that the increased cooling rate facilitates the formation of BCC-structured phase, making the solidification further deviate away from the equilibrium condition. As a result, the V600, V800, and V1000 alloys may become hypoeutectic HEAs, leading to the formation of isolated B2/A2 phases (primary phases) in the microstructures (Fig. $3 \mathrm{~d}, \mathrm{f}$ and $\mathrm{h}$ ). Due to the low stress accommodation capacity of the isolated B2/A2 phases, the cracks will initiate inside the hard and brittle B2/A2 phases. This also suggests that the cracks which appear in the isolated B2/A2 phases belong to cold cracks.

Generally, the steep temperature gradient during SLM reduces or eliminates constitutional supercooling $\left(\Delta T_{\mathrm{CS}}\right)$. Consequently, the nucleation events in front of the S/L interface are suppressed and columnar grains are favored. However, the $\Delta T_{\mathrm{CS}}$ is proportional to the $Q$ value ( $Q$ is the growth restriction factor) [35]:

$\Delta T_{\mathrm{CS}}=Q \cdot \Omega$,

where $\Omega$ is the dimensionless supersaturation parameter. During the eutectic reaction, the enrichment of $\mathrm{Cr}$ and $\mathrm{Fe}$ solutes with large $Q$ values in the liquid can also rapidly develop a large constitutional supercooling zone ahead of the S/L interface, locally reducing the nucleation barrier for crystallization, which causes the increased amount of nucleation sites and makes equiaxed grain nucleation possible [36]. Moreover, due to the use of mixed powders 
and the steep temperature gradient, Marangoni convection is more active, causing rapid fluid flow and mix inside the molten pool. As a result, the temperature gradients $(G)$ across the molten pools will dynamically decrease during layer solidification. Consequently, $\Delta T_{\mathrm{CS}}$ surpasses the nucleant potency of particles $\left(\Delta T_{\mathrm{N}}\right)$ presented in this zone, then constitutional supercooling is permitted and equiaxed grain nucleation occurs, as illustrated by the schematic diagram in Fig. $8 \mathrm{a}$.

For the as-built V600 sample, a mixed thinner columnar and equiaxed grains are generated (Fig. $3 \mathrm{~d}$ ) due to the reduced $\Delta T_{\mathrm{CS}}$ caused by the increased $G$. But further increasing the scanning speed results in a quicker cooling rate, and more BCC phase including the $\mathrm{Cr}$-rich A2 nano-precipitates will be favored (Fig. 6b). Considering the strong evidence that finer equiaxed grains do form in the as-built V1000 sample (Fig. 3h), more $\mathrm{Cr}$ and Fe atoms should be rejected into the liquid to establish a higher concentration gradient ahead of the S/L interface, which in turn enhances the $\Delta T_{\mathrm{CS}}$. Consequently, sufficient $\Delta T_{\mathrm{CS}}$ still can efficiently offset the negative influence of the steep temperature gradient, as illustrated by the schematic diagram in Fig. 8b. Also, partially unmelted powder particles caused by the high scanning speed provide the potent nuclei [37]. This facilitates the heterogeneous nucleation and results in finer equiaxed grains. Generally, coarse columnar grains easily cause hot tearing at the grain boundaries during solidification [18], but the fine equiaxed grains can effectively suppress hot tearing and withstand the residual stress, thus improving the processability. Unfortunately, more microcracks occur in the microstructures with the increase of the scanning speed. Also, the cracks only initiate and propagate within the isolated B2/A2 phases. Therefore, it can be confirmed that the cracks which appear in the V600, V800 and V1000 samples belong to the cold cracks. The cold cracking is attributed to the appearance of isolated B2/A2 brittle phases with less stress accommodation capacity. Thus, it can be concluded that the synergy of the near-eutectic DP nano-structures and near-equiaxed grains instead of columnar ones effectively eliminates the cracks.

\section{Mechanical properties and deformed microstructure of the as-built HEA}

Fig. 9 shows the engineering stress-strain diagram of the as-built samples at different scanning speeds. Due to the existence of isolated B2/A2 brittle phases and cracks in the V600, V800 and V1000 samples, their mechanical properties are deteriorated. Also, when the scanning
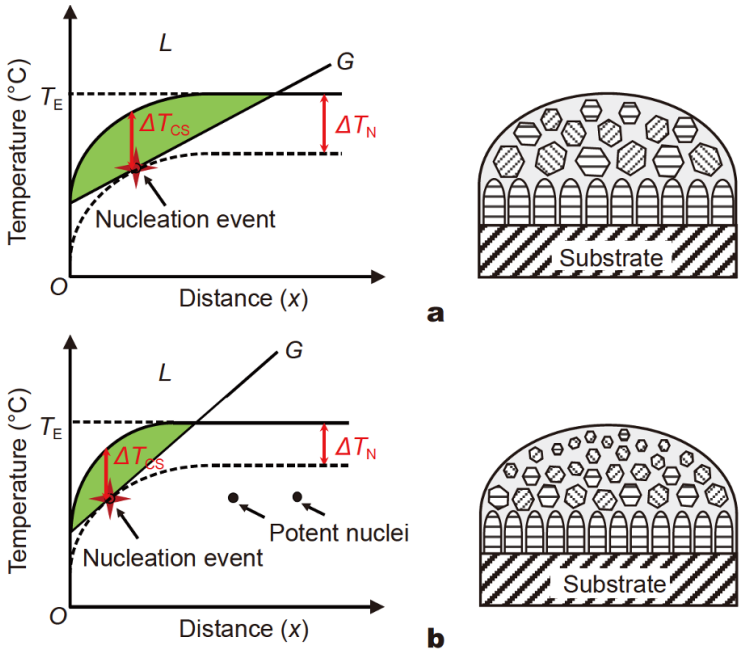

Figure 8 Schematic illustration of grain growth mechanisms for the asbuilt samples: (a) V400; (b) V1000. $T_{\mathrm{E}}$ represents the equilibrium solidification temperature.

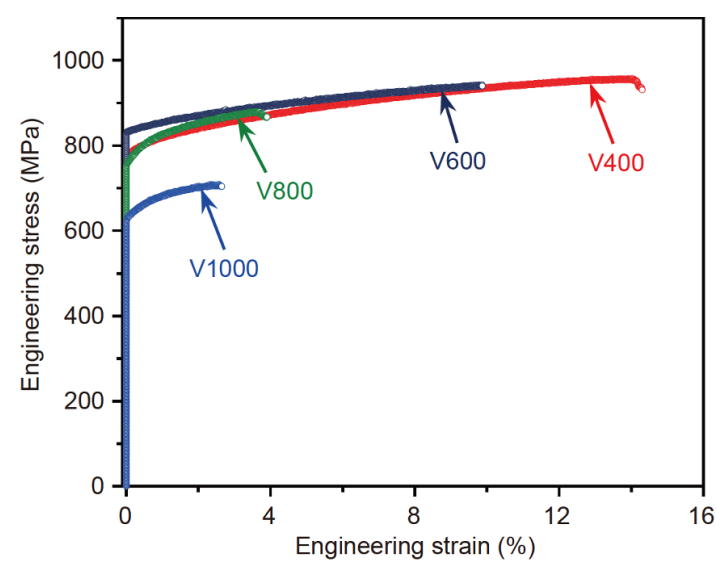

Figure 9 Engineering stress-strain diagram of the as-built samples at different scanning speeds.

speed increases, because the number of cracks increases in the microstructures, the strength is found to decrease with the increasing scanning speed. Moreover, the V400 sample exhibits the best strength-ductility combination (yield strength $\sim 775 \mathrm{MPa}$, tensile strength $\sim 957 \mathrm{MPa}$, elongation $\sim 14.3 \%$ ). This surpasses those of the as-cast as well as cold-rolled plus annealed $\mathrm{AlCuFeCrNi}$ alloys [38]. These results imply that different energy inputs may be the main factor that leads to the varied microstructures and properties for the SLM-built HEAs.

Considering that the V400 sample exhibits the best strength-ductility combination, the deformed microstructures of the V400 sample was studied by TEM. It 
should be noted that the loading direction of tensile specimens is perpendicular to the build direction. The post-deformed microstructures on the $X Y$ plane (which has been schematically illustrated in Fig. 1b) are observed to better evaluate the strengthening mechanisms. A bright-field TEM image of the deformed V400 sample on the $X Y$ plane is shown in Fig. 10a. The FCC phase is decorated with high densities of dislocations, while the B2 phase possesses relatively low dislocation density. This validates that dislocation-mediated plasticity is dominant in the FCC phase during tension. Also, as marked by white arrows in Fig. 10a, geometrically necessary dislocations (GNDs) in the FCC cells cannot transmit across the B2 phases and pile up around the cell boundaries, which can generate back stress. Different from the deformation heterogeneity at the grain scale reported previously $[39,40]$, this deformation heterogeneity is mainly at sub-micron scale inside the grains. Thus the resultant back stress should be appropriately called intragranular back stress [41], which will be evaluated subsequently. According to the TEM images on the $X Y$ plane, the average thickness of the $\mathrm{B} 2$ phase is determined as $\sim 140 \mathrm{~nm}$ and the mean size of the FCC cells is determined as $\sim 490 \mathrm{~nm}$. The soft FCC cell is nearly encircled by the hard B2 phase. In such a scenario, the soft FCC cells cannot change their shape as required to deform plastically until the hard B2 phase is plastically de- forming $[39,42,43]$. Consequently, the intragranular back stress may make the soft FCC cells almost stronger than the hard $\mathrm{B} 2$ phase.

A bright-field TEM image of the $\mathrm{B} 2$ phase near the FCC cell is shown in Fig. 10b. Fig. 10c and d respectively display the HRTEM micrographs from the blue and red boxed regions in Fig. 10b. It is found that the A2 nanoprecipitates are sheared by dislocations, which generates stacking faults (SFs) within the A2 nano-precipitates, as verified by the stretched FFT patterns boxed by green solid lines in Fig. 10c and d. In addition to SFs, deformed nano-twins are produced inside the $\mathrm{A} 2$ nano-precipitates. The nano-twin boundaries pointed by the red dashed lines are located on the (1I2) twin planes determined by the FFT pattern in Fig. 10d. The occurrence of deformed nano-twins further confirms that the dislocations pass through the A2 nano-precipitate via a particle shearing mechanism instead of a dislocation bypassing mechanism. Since the A2 nano-precipitates exhibit coherent relation with the B2 phase and their particle diameters are mostly no larger than $12 \mathrm{~nm}$, the A2 nano-precipitates are expected to enhance the strength through a particle shearing mechanism [44]. Therefore, abundant A2 nanoprecipitates embedded in the $\mathrm{B} 2$ matrix can further facilitate the generation of GNDs and thus the strain hardening. The inverse FFT (IFFT) image (Fig. 10e) confirms the high-density dislocations (T marks) in the
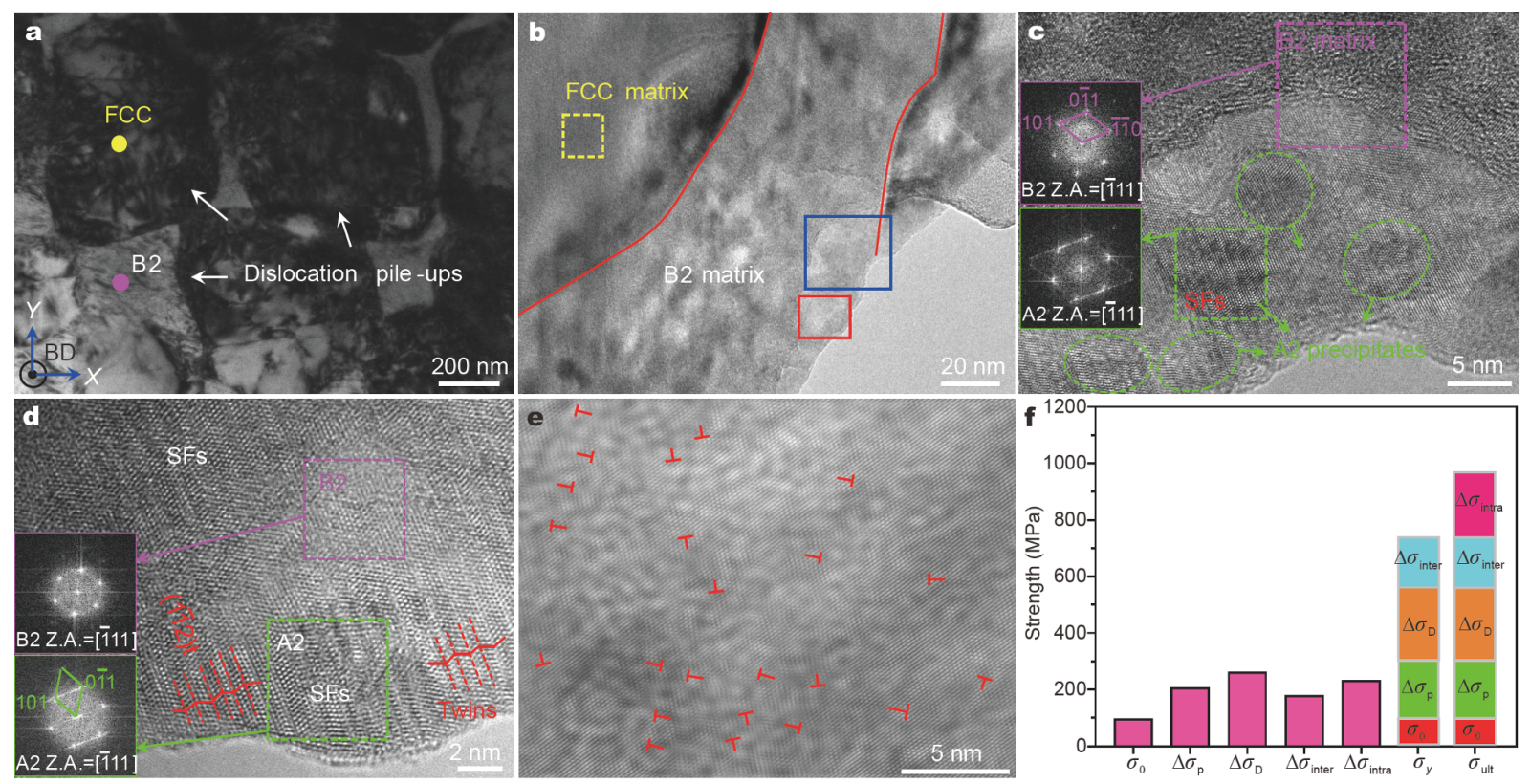

Figure 10 (a, b) Bright-field TEM images on the XY plane of the post-deformed V400 sample; (c, d) HRTEM images of the blue and red boxed zones in (b), respectively. SFs and twins are discovered; (e) IFFT image corresponding to the yellow dashed box in (b), the dislocations are marked by the red ' $T$ '; (f) calculated strength contributions. 
post-deformed FCC cells.

\section{Strengthening mechanisms and evaluation}

Because the V400 sample possesses no cracks, its mechanical properties can be well reflected. Also, the V400 sample exhibits the best strength-ductility combination. Therefore, the strengthening mechanisms of the V400 sample are studied and evaluated in this section. To understand the physical nature of tensile hardening, the flow stress is divided into two parts [41]:

$\sigma=\sigma_{\mathrm{ef}}+\sigma_{\mathrm{b}}$,

where $\sigma_{\text {ef }}$ is the effective stress induced by short-range interactions like friction stress $\sigma_{0}$, precipitation hardening $\Delta \sigma_{\mathrm{p}}$ and dislocation strengthening $\Delta \sigma_{\mathrm{D}}$ in this work. $\sigma_{\mathrm{b}}$ is the back stress related to the long-range interaction with mobile dislocations.

The precipitation hardening $\Delta \sigma_{\mathrm{p}}$ is estimated according to a simple composite model:

$\Delta \sigma_{\mathrm{p}}=\sigma_{\mathrm{I}} \cdot f_{\mathrm{I}}+\sigma_{\mathrm{II}} \cdot f_{\mathrm{I}}$,

where $\sigma_{\mathrm{I}}$ and $\sigma_{\mathrm{II}}$ are the intrinsic strength resulted from the precipitation hardening inside the FCC and $\mathrm{B} 2$ phases, respectively. $f_{\mathrm{I}}$ and $f_{\mathrm{II}}$ denote the average area fractions of FCC and B2 phases, respectively. Since almost no secondary phases are detected within the FCC phase (see the HAADF-STEM micrograph in Fig. $4 \mathrm{~b}$ ), the $\sigma_{\mathrm{I}} \cdot f_{\mathrm{I}}$ term in Equation (3) equals zero. $f_{\text {II }}$ is calculated as about $22.2 \%$ using $f_{\mathrm{II}}=t /(\lambda+t)$, where $t$ is the thickness $(\sim 140 \mathrm{~nm})$ of the B2 phase and $\lambda$ is the spacing $(\sim 490 \mathrm{~nm})$ between hard B2 zones based on the TEM observation. A similar composite model was also used in Ref. [45].

In the B2 phase, since the near-spherical A2 nanoprecipitates are sheared by the glide of dislocations, the particle-matrix coherency $\left(\Delta \sigma_{\mathrm{CS}}\right)$, modulus mismatch $\left(\Delta \sigma_{\mathrm{MS}}\right)$ and atomic ordering $\left(\Delta \sigma_{\mathrm{OS}}\right)$ factors are considered to evaluate the precipitation hardening effect [46]:

$\Delta \sigma_{\mathrm{CS}}=M \cdot \alpha_{\varepsilon}(G \cdot \varepsilon)^{3 / 2}\left(\frac{r f}{0.5 G b}\right)^{1 / 2}$,

$\Delta \sigma_{\mathrm{MS}}=M \cdot 0.0055(\Delta G)^{3 / 2}\left(\frac{2 f}{G}\right)^{1 / 2}\left(\frac{r}{b}\right)^{3 m / 2-1}$,
$\Delta \sigma_{\mathrm{OS}}=M \cdot 0.81 \frac{\gamma_{\mathrm{APB}}}{2 b}\left(\frac{3 \pi f}{8}\right)^{1 / 2}$,

where $b=0.248 \mathrm{~nm}$ is the Burger's vector obtained from the XRD pattern of the V400 sample, $m=0.85$ [47], $\varepsilon \approx$ $2 / 3 \cdot(\Delta a / a)$ is the constrained lattice misfit, $\Delta a / a=0.0017$ is calculated from the XRD pattern, $\Delta a$ is the difference of lattice constant between the A2 nano-precipitate and the B2 matrix. $r=8 \mathrm{~nm}$ and $f=58.5 \%$ are the mean particle size and relative volume fraction of the A2 nanoprecipitates inside the $\mathrm{B} 2$ matrix obtained from the TEM observation, respectively. Other parameters are explained and listed in Table 1 . Note that the Taylor factor $(M)$ values of the FCC and BCC phases with random textures are adopted since the deformed microstructures corresponding to the $X Y$ plane possess random or weak textures. Using the Equations (4-6), the strength increments caused by the $8 \mathrm{~nm}$-sized A2 nano-precipitate in the B2 matrix are calculated as $\Delta \sigma_{\mathrm{CS}}=125.8 \mathrm{MPa}, \Delta \sigma_{\mathrm{MS}}=$ $24.1 \mathrm{MPa}$, and $\Delta \sigma_{\mathrm{OS}}=921.6 \mathrm{MPa}$, respectively. Obviously, the precipitation hardening is mainly from the atomic ordering strengthening which occurs during shearing. Then, using Equation (3), the precipitation hardening $\Delta \sigma_{\mathrm{p}}$ caused by the $\mathrm{A} 2$ nano-precipitates is calculated as about $204.6 \mathrm{MPa}$ using $\Delta \sigma_{\mathrm{OS}} f_{\mathrm{II}}$. This demonstrates that the shearing mechanism dominates when the precipitates are coherent and small.

The dislocation hardening is evaluated using a BaileyeHirsch formula [48]:

$\Delta \sigma_{\mathrm{D}}=M \alpha G b \rho^{1 / 2}$,

where $b=0.255 \mathrm{~nm}$ is obtained from the XRD pattern of V400 sample, $\rho$ is the dislocation density in the FCC phase of the as-printed sample, which is roughly determined to be $4.2 \times 10^{14} \mathrm{~m}^{-2}$ from the XRD pattern by using the Williamson-Hall method [49]. Note that the dislocation density in the BCC-structured phase of the asprinted sample is quite low, thus the printing-induced dislocation hardening in the B2 phase is ignored. Then using the data in Table 1, the increment of dislocation hardening $\left(\Delta \sigma_{\mathrm{D}}\right)$ is about $259.0 \mathrm{MPa}$ calculated by Equation (7).

The back stress $\sigma_{\mathrm{b}}$ is caused by two incompatibility le-

Table 1 Data used for the strength calculations [45,50]: Taylor factor $(M)$, constant $(\alpha)$, shear modulus of matrix $(G)$, constant $\left(\alpha_{\varepsilon}\right)$, shear modulus mismatch between the precipitate and matrix $(\Delta G)$, anti-phase boundary energy of the precipitate $\left(\gamma_{\mathrm{APB}}\right)$

\begin{tabular}{ccccccc}
\hline Phase & $M$ & $\alpha$ & $G(\mathrm{GPa})$ & $\alpha_{\varepsilon}$ & $\Delta G(\mathrm{GPa})$ & $\gamma_{\mathrm{APB}}\left(\mathrm{J} \mathrm{m}^{-2}\right)$ \\
\hline FCC & 3.06 & 0.2 & 81 & - & - & - \\
BCC & 2.73 & 0.25 & 83 & 2.6 & 3 & 0.25 \\
\hline
\end{tabular}


vels, i.e., intergranular and intragranular. The plastic strain incompatibility between the grains causes intergranular back stress. In this study, since the grain size distributions are nearly homogenous, the intergranular back stress $\left(\Delta \sigma_{\text {inter }}\right)$ is mainly related to grain boundary (GB). The GB separates the grains with two different crystallographic orientations and constitutes a hard zone, which can resist the slip of dislocations emitted from Frank Read sources and cause piling up of dislocation against the GBs. Consequently, the long-range internal stress named as intergranular back stress $\left(\Delta \sigma_{\text {inter }}\right)$ is induced. At the yield point, the $\Delta \sigma_{\text {inter }}$ can be obtained as about $216.4 \mathrm{MPa}$ using $\Delta \sigma_{\text {inter }}=\sigma_{y}-\sigma_{0}-\Delta \sigma_{\mathrm{p}}-\Delta \sigma_{\mathrm{D}}$, where $\sigma_{y}$ is the yield stress and equals $775 \mathrm{MPa}$, and the friction stress $\sigma_{0}$ equals $95 \mathrm{MPa}$ [51]. In fact, the increased strength from the $\Delta \sigma_{\text {inter }}$ is similar to the GB hardening effect $\left(\Delta \sigma_{\mathrm{G}}\right)$. From the Hall-Petch relationship, the $\Delta \sigma_{\mathrm{G}}$ can be calculated to be about 177.3 MPa using $\Delta \sigma_{\mathrm{G}}=$ $k d^{-1 / 2}$, where $d$ is the mean grain size $(\sim 21.6 \mu \mathrm{m}), k=$ $824 \mathrm{MPa} \mu \mathrm{m}$ is the Hall-Petch slope [51].

As observed by the bright-field TEM, at the ultimate tensile strain, the soft FCC cells and hard B2 phases lead to the severe plastic strain incompatibility inside grains, thus producing the intragranular back stress $\left(\Delta \sigma_{\text {intra }}\right)$. According to the physical essence of intragranular back stress [41], the $\Delta \sigma_{\text {intra }}$ can be approximately calculated:

$\Delta \sigma_{\text {intra }}=f_{\mathrm{G}} f_{\text {II }}\left(M_{i} \alpha_{i} G_{i} b_{i} \sqrt{\rho_{i}}-M_{j} \alpha_{j} G_{j} b_{j} \sqrt{\rho_{j}}\right)$,

where subscript $i$ and $j$ correspond to FCC and B2, respectively. The Taylor factor $(M)$, constant $(\alpha)$ and shear modulus $(G)$ for the FCC and B2 phases are listed in Table 1 . The Burger's vector $(b)$ values of the FCC and B2 phases have also been determined as 0.255 and $0.248 \mathrm{~nm}$, respectively. $f_{\mathrm{II}}$ is the average area fraction of the $\mathrm{B} 2$ phase, which has been calculated as about $22.2 \%$. $f_{\mathrm{G}}$ is the fraction of grains where heterogeneous deformation occurs and is assumed to be close to $1 . \rho_{i}$ and $\rho_{j}$ are the dislocation densities in the post-deformed FCC cells and B2 phase and respectively determined as about $2.4 \times 10^{15}$ and $2.1 \times 10^{14} \mathrm{~m}^{-2}$ according to the IFFT images (Fig. 10e shows an example). Using Equation (8), $\Delta \sigma_{\text {intra }}$ is calculated as about $229.6 \mathrm{MPa}$. This indicates that the global back stresses collected in the whole sample are high enough, which facilitates to enhance the macroscopic strength and prevent the local necking during tensile deformation [39].

In fact, with the increase of the plastic strain, $\Delta \sigma_{\text {intra }}$ will gradually increase. The $\Delta \sigma_{\text {intra }}$ will become important at the ultimate tensile strain where the heterogeneous distribution of dislocation is aggravated inside the grains. So if we adopt the assumption that at large strains, the effective stress $\left(\sigma_{\mathrm{ef}}\right)$ is independent of plastic strain and equals yield stress $\left(\sigma_{y}\right)$ [41]. Then at the ultimate tensile strain, the $\Delta \sigma_{\text {intra }}$ can be approximately determined as 182.0 MPa using $\Delta \sigma_{\text {intra }} \approx \sigma_{\text {ult }}-\sigma_{y}$, where $\sigma_{\text {ult }}$ is the ultimate tensile stress. This measured value is lower than that calculated by Equation (8) because the $\sigma_{\text {ef }}$ will actually decrease with the increase of the plastic strain owing to the activation of dislocation slip. Note that the solid solution hardening is ignored in this study, since it makes a much small contribution to the total increment of strength [45,50]. As shown in Fig. 10f, the calculated $\sigma_{y}(\sim 735.9 \mathrm{MPa})$ and $\sigma_{\text {ult }}(\sim 965.5 \mathrm{MPa})$ are reasonably consistent with the experimental values. Therefore, in addition to the precipitation hardening and dislocation hardening, the back stresses including the intergranular and intragranular back stresses also significantly contribute to the high tensile properties of the SLM-fabricated $\mathrm{AlCrCuFeNi}_{3}$ DP-HEA.

\section{CONCLUSION}

In summary, different energy inputs lead to the varied microstructures and properties for the SLM-built AlCr$\mathrm{CuFeNi}_{3.0}$ DP-HEA. The AlCrCuFeNi $\mathrm{Al}_{3.0}$ DP-HEA fabricated by SLM at the scanning speed of $400 \mathrm{~mm} \mathrm{~s}^{-1}$ falls into the eutectic coupled zone. The rapid and continuous alternating nucleation and growth during eutectic reaction lead to the formation of FCC (Fe-Cr rich) and B2 (Cu-Al rich) DP nano-structures. The $\mathrm{Cr}$-rich $\mathrm{A} 2$ nanoprecipitates are formed via solid-state decomposition of the B2 phase. The constitutional supercooling induced by $\mathrm{Cr}$ and $\mathrm{Fe}$ solutes enrichment ahead of the S/L interface facilitates the heterogeneous nucleation and nearequiaxed grain formation. The synergy of the near-eutectic DP nano-structures and near-equiaxed grains instead of columnar ones can effectively eliminate the cracks. In addition to dislocation hardening, precipitation hardening (dislocation shearing A2 nano-precipitates), the back stresses containing the intergranular and intragranular back stresses also significantly contribute to the high tensile properties of the SLM-built AlCrCuFe$\mathrm{Ni}_{3.0}$ DP-HEA. Our work can offer guidelines for optimizing the SLM process parameters to develop HEAs with novel performance.

Received 11 February 2020; accepted 7 March 2020;

published online 8 April 2020

1 Yeh JW, Chen SK, Lin SJ, et al. Nanostructured high-entropy alloys with multiple principal elements: Novel alloy design concepts and outcomes. Adv Eng Mater, 2004, 6: 299-303 
$2 \mathrm{Wu}$ J, Liu B, Cui Y, et al. Polymorphism and superconductivity in the V-Nb-Mo-Al-Ga high-entropy alloys. Sci China Mater, 2020, 63: 823-831

3 Miracle DB, Senkov ON. A critical review of high entropy alloys and related concepts. Acta Mater, 2017, 122: 448-511

4 Zhang W, Liaw PK, Zhang Y. Science and technology in highentropy alloys. Sci China Mater, 2018, 61: 2-22

5 Liu J, Guo X, Lin Q, et al. Excellent ductility and serration feature of metastable $\mathrm{CoCrFeNi}$ high-entropy alloy at extremely low temperatures. Sci China Mater, 2019, 62: 853-863

6 Zhu ZG, An XH, Lu WJ, et al. Selective laser melting enabling the hierarchically heterogeneous microstructure and excellent mechanical properties in an interstitial solute strengthened high entropy alloy. Mater Res Lett, 2019, 7: 453-459

7 Gwalani B, Gorsse S, Choudhuri D, et al. Tensile yield strength of a single bulk $\mathrm{Al}_{0.3} \mathrm{CoCrFeNi}$ high entropy alloy can be tuned from $160 \mathrm{MPa}$ to $1800 \mathrm{MPa}$. Scripta Mater, 2019, 162: 18-23

8 Guo L, Gu J, Gong X, et al. CALPHAD aided design of high entropy alloy to achieve high strength via precipitate strengthening. Sci China Mater, 2020, 63: 288-299

9 Park JM, Choe J, Kim JG, et al. Superior tensile properties of 1\%C$\mathrm{CoCrFeMnNi}$ high-entropy alloy additively manufactured by selective laser melting. Mater Res Lett, 2020, 8: 1-7

$10 \mathrm{Wu} \mathrm{W}$, Zhou R, Wei B, et al. Nanosized precipitates and dislocation networks reinforced C-containing CoCrFeNi high-entropy alloy fabricated by selective laser melting. Mater Charact, 2018, 144: 605-610

11 Shukla S, Choudhuri D, Wang T, et al. Hierarchical features infused heterogeneous grain structure for extraordinary strengthductility synergy. Mater Res Lett, 2018, 6: 676-682

12 Li R, Wang Z, Guo Z, et al. Graded microstructures of Al-Li-Mg$\mathrm{Zn}-\mathrm{Cu}$ entropic alloys under supergravity. Sci China Mater, 2019, 62: 736-744

13 Yang T, Zhao YL, Liu WH, et al. Ductilizing brittle high-entropy alloys via tailoring valence electron concentrations of precipitates by controlled elemental partitioning. Mater Res Lett, 2018, 6: 600606

14 Shi P, Ren W, Zheng T, et al. Enhanced strength-ductility synergy in ultrafine-grained eutectic high-entropy alloys by inheriting microstructural lamellae. Nat Commun, 2019, 10: 489

15 Li F, Wang Z, Zeng X. Microstructures and mechanical properties of Ti6Al4V alloy fabricated by multi-laser beam selective laser melting. Mater Lett, 2017, 199: 79-83

16 Luo S, Huang W, Yang H, et al. Microstructural evolution and corrosion behaviors of Inconel 718 alloy produced by selective laser melting following different heat treatments. Addit Manufact, 2019, 30: 100875

17 Brif Y, Thomas M, Todd I. The use of high-entropy alloys in additive manufacturing. Scripta Mater, 2015, 99: 93-96

18 Sun Z, Tan XP, Descoins M, et al. Revealing hot tearing mechanism for an additively manufactured high-entropy alloy via selective laser melting. Scripta Mater, 2019, 168: 129-133

19 Zhou PF, Xiao DH, Wu Z, et al. $\mathrm{Al}_{0.5} \mathrm{FeCoCrNi}$ high entropy alloy prepared by selective laser melting with gas-atomized pre-alloy powders. Mater Sci Eng-A, 2019, 739: 86-89

20 Li R, Niu P, Yuan T, et al. Selective laser melting of an equiatomic CoCrFeMnNi high-entropy alloy: processability, non-equilibrium microstructure and mechanical property. J Alloys Compd, 2018, 746: $125-134$

21 Zhu ZG, Nguyen QB, Ng FL, et al. Hierarchical microstructure and strengthening mechanisms of a CoCrFeNiMn high entropy alloy additively manufactured by selective laser melting. Scripta Mater, 2018, 154: 20-24

$22 \mathrm{Xu} \mathrm{Z}$, Zhang $\mathrm{H}, \mathrm{Li} \mathrm{W}$, et al. Microstructure and nanoindentation creep behavior of CoCrFeMnNi high-entropy alloy fabricated by selective laser melting. Addit Manufact, 2019, 28: 766-771

23 Zhou R, Liu Y, Zhou C, et al. Microstructures and mechanical properties of C-containing FeCoCrNi high-entropy alloy fabricated by selective laser melting. Intermetallics, 2018, 94: 165-171

24 Zhou R, Liu Y, Liu B, et al. Precipitation behavior of selective laser melted $\mathrm{FeCoCrNiC}_{0.05}$ high entropy alloy. Intermetallics, 2019, 106: $20-25$

25 Zhang M, Zhou X, Wang D, et al. AlCoCuFeNi high-entropy alloy with tailored microstructure and outstanding compressive properties fabricated via selective laser melting with heat treatment. Mater Sci Eng-A, 2019, 743: 773-784

26 Luo S, Gao P, Yu H, et al. Selective laser melting of an equiatomic $\mathrm{AlCrCuFeNi}$ high-entropy alloy: Processability, non-equilibrium microstructure and mechanical behavior. J Alloys Compd, 2019, 771: 387-397

27 Niu PD, Li RD, Yuan TC, et al. Microstructures and properties of an equimolar AlCoCrFeNi high entropy alloy printed by selective laser melting. Intermetallics, 2019, 104: 24-32

28 Luo S, Zhao C, Su Y, et al. Selective laser melting of dual phase $\mathrm{AlCrCuFeNi}_{x}$ high entropy alloys: formability, heterogeneous microstructures and deformation mechanisms. Addit Manufact, 2020, 31: 100925

29 Wang Z, Guan K, Gao M, et al. The microstructure and mechanical properties of deposited-IN718 by selective laser melting. J Alloys Compd, 2012, 513: 518-523

30 Guo S, Ng C, Liu CT. Anomalous solidification microstructures in Co-free $\mathrm{Al}_{x} \mathrm{CrCuFeNi}_{2}$ high-entropy alloys. J Alloys Compd, 2013, 557: 77-81

31 Jiang $\mathrm{H}, \mathrm{Han} \mathrm{K}, \mathrm{Gao} \mathrm{X}$, et al. A new strategy to design eutectic high-entropy alloys using simple mixture method. Mater Des, 2018, 142: 101-105

32 Lu Y, Jiang H, Guo S, et al. A new strategy to design eutectic highentropy alloys using mixing enthalpy. Intermetallics, 2017, 91: 124-128

33 Jin $\mathrm{X}$, Zhou $\mathrm{Y}$, Zhang L, et al. A new pseudo binary strategy to design eutectic high entropy alloys using mixing enthalpy and valence electron concentration. Mater Des, 2018, 143: 49-55

34 Takeuchi A, Inoue A. Classification of bulk metallic glasses by atomic size difference, heat of mixing and period of constituent elements and its application to characterization of the main alloying element. Mater Trans, 2005, 41: 2817-2829

35 Zhang D, Qiu D, Gibson MA, et al. Additive manufacturing of ultrafine-grained high-strength titanium alloys. Nature, 2019, 576: 91-95

36 Bermingham MJ, McDonald SD, StJohn DH, et al. Segregation and grain refinement in cast titanium alloys. J Mater Res, 2009, 24: 1529-1535

37 Wang T, Zhu YY, Zhang SQ, et al. Grain morphology evolution behavior of titanium alloy components during laser melting deposition additive manufacturing. J Alloys Compd, 2015, 632: 505513

38 Ma SG, Qiao JW, Wang ZH, et al. Microstructural features and tensile behaviors of the $\mathrm{Al}_{0.5} \mathrm{CrCuFeNi}_{2}$ high-entropy alloys by cold rolling and subsequent annealing. Mater Des, 2015, 88: 1057-1062 $39 \mathrm{Wu}$ X, Zhu Y. Heterogeneous materials: a new class of materials 
with unprecedented mechanical properties. Mater Res Lett, 2017, 5: $527-532$

40 Wu X, Yang M, Yuan F, et al. Heterogeneous lamella structure unites ultrafine-grain strength with coarse-grain ductility. Proc Natl Acad Sci USA, 2015, 112: 14501-14505

41 Feaugas X. On the origin of the tensile flow stress in the stainless steel AISI $316 \mathrm{~L}$ at $300 \mathrm{~K}$ : Back stress and effective stress. Acta Mater, 1999, 47: 3617-3632

42 Zhu Y, Wu X. Perspective on hetero-deformation induced (HDI) hardening and back stress. Mater Res Lett, 2019, 7: 393-398

43 Zhao Y, Zhang J, Wang Y, et al. Size-dependent mechanical properties and deformation mechanisms in $\mathrm{Cu} / \mathrm{NbMoTaW}$ nanolaminates. Sci China Mater, 2020, 63: 444-452

44 Jansson B, Melander A. On the critical resolved shear stress from misfitting particles. Scripta Metall, 1978, 12: 497-498

45 He JY, Wang H, Huang HL, et al. A precipitation-hardened highentropy alloy with outstanding tensile properties. Acta Mater, 2016, 102: 187-196

46 Booth-Morrison C, Dunand DC, Seidman DN. Coarsening resistance at $400^{\circ} \mathrm{C}$ of precipitation-strengthened $\mathrm{Al}-\mathrm{Zr}-\mathrm{Sc}-\mathrm{Er}$ alloys. Acta Mater, 2011, 59: 7029-7042

47 Nembach E. Precipitation hardening caused by a difference in shear modulus between particle and matrix. Phys Stat Sol A, 1983, 78: $571-581$

48 Courtney TH. Mechanical Behavior of Materials. Waveland: Long Grove Press, 2005

49 Williamson GK, Smallman RE. III. Dislocation densities in some annealed and cold-worked metals from measurements on the Xray Debye-Scherrer spectrum. Philos Mag, 1956, 1: 34-46

50 Ma Y, Hao J, Jie J, et al. Coherent precipitation and strengthening in a dual-phase $\mathrm{AlNi}_{2} \mathrm{Co}_{2} \mathrm{Fe}_{1.5} \mathrm{Cr}_{1.5}$ high-entropy alloy. Mater Sci Eng-A, 2019, 764: 138241

51 Gwalani B, Soni V, Lee M, et al. Optimizing the coupled effects of Hall-Petch and precipitation strengthening in a $\mathrm{Al}_{0.3} \mathrm{CoCrFeNi}$ high entropy alloy. Mater Des, 2017, 121: 254-260

Acknowledgements This work was supported by the Pre-research Fund Project of Ministry of Equipment and Development of China (61409230301), and the Fundamental Research Funds for the Central Universities (2019kfyXMPY005 and 2019kfyXKJC042). The authors thank the Analytical and Testing Center of HUST for SEM, EBSD, EPMA and TEM measurement.

Author contributions Wang $\mathrm{Z}$ conceived the experiments. Wang Z, Luo $S$ and $S u Y$ contributed to the theoretical analysis. Luo $S$ performed the experiments and wrote the paper. All authors discussed the results and commented on the manuscript.

Conflict of interest The authors declare no conflict of interest.

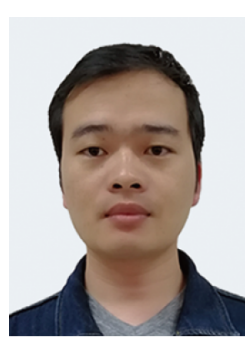

Shuncun Luo received his Master's degree from Central South University in 2017. Currently, he is a $\mathrm{PhD}$ candidate at Wuhan National Laboratory for Optoelectronics, Huazhong University of Science and Technology (HUST), China. His current research interest focuses on the laser additive manufacturing of advanced structural materials, such as high-entropy alloy and highentropy light alloy.

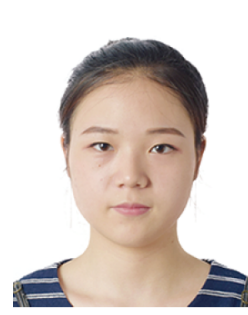

Yue Su received her bachelor's degree from Wuhan University of Science and Technology in 2018. Currently, she is a Master degree candidate at Wuhan National Laboratory for Optoelectronics, HUST, China. Her current research interest focuses on the laser additive manufacturing of high-entropy alloy.

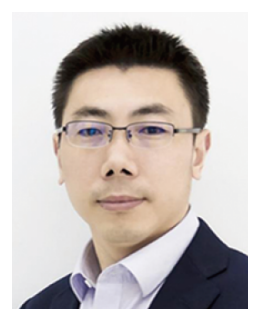

Zemin Wang received his $\mathrm{PhD}$ degree in materials science from HUST in 2003. He did scientific research in the Multidisciplinary Research Center for Materials Processing at the University of Birmingham from 2007 to 2008 . He has been a professor of materials science and optical engineering at HUST since 2011. His research interests include laser additive manufacturing, laser materials processing, materials science \& engineering, and laser manufacturing engineering.

\section{激光选区熔化增材制造双相高熵合金组织调控与 强化机制}

骆顺存, 苏悦, 王泽敏

摘要 双相高熵合金因具有优异的综合力学性能而备受关注. 本文 对激光选区熔化制备的 $\mathrm{AlCrCuFeNi}_{3.0}$ 双相高摘合金微观组织进行 了调控, 揭示了分层组织形成的机理. 研究发现, 当激光扫描速度为 $400 \mathrm{~mm} \mathrm{~s}^{-1}$ 时, $\mathrm{AlCrCuFeNi}$. 成分进入共生区, 随着扫描速度的增 加, 冷却速率增加, 该成分将偏离共生区. 固液前沿 $\mathrm{Cr}$ 和 $\mathrm{Fe}$ 溶质的 富集产生成分过冷, 有利于异质形核和等轴晶的形成. 近共晶组织 与近等轴晶的共同作用有效地抑制了开裂. 在拉伸变形过程中, 发 现了类似于晶界强化的晶间背应力强化现象. 同时, 由面心立方和 有序体心立方 (B2)双相纳米结构组成的近共晶组织导致晶内塑性 变形不协调, 从而产生晶内背应力. 而B2相中富铬的纳米析出相发 生位错剪切变形, 可以强化背应力. 此外, 本文对多种强化机制进行 了物理评估, 发现背应力强化显著提高了该合金的力学性能. 